\title{
Short stature among children undergoing cardiac surgery for congenital heart defects
}

\author{
Catalina Le Roy, M.D. ${ }^{a}$, Guillermo Larios, M.D. ${ }^{b}$, Cristian Clavería, M.D. ${ }^{b}$ and \\ Daniel Springmüller, M.D. ${ }^{b}$
}

\begin{abstract}
Introduction. Children with congenital heart diseases (CHDs) suffer from malnutrition because of nutritional deficiencies, being short stature the possible long-term consequence.

Objective. To describe the presence of short stature among children undergoing cardiac surgery for CHDs.

Population and methods. Retrospective study. Children undergoing cardiac surgery with cardiopulmonary bypass pump between 2009 and 2013 were included.

Preterm infants, carriers of genetic syndromes or other disease with nutritional compromise were excluded. Demographic data, type of $\mathrm{CHD}$, admission surgery and anthropometric assessment using the WHO standards were studied. Short stature was defined as lenght/ height for age $\mathrm{Z}$ score $<-2$ standard deviations, by sex.

Results. A total of 640 children were studied; $361(56.4 \%)$ were boys; median age: 8 months (IQR: $1.9 ; 34.6$ ); 66 children underwent $>1$ surgery; 27 of them $(40.9 \%)$ had hypoplasia of the left ventricle. There were $358(55.9 \%)$ infants with cyanotic CHDs, 196 (30.6\%) with univentricular physiology. The median HAZ was -0.9 (IQR: $-1.9 ;-0.1)$; $135(21.1 \%)$ had a short stature, $11 \%$ of newborn infants and $24.1 \%$ of older than one month old. A higher frequency of short stature was observed in 4 out of 6 children who underwent complete repair of the atrioventricular canal, in 15 out of 39 infants with repair of tetralogy of Fallot, in 8 out of 25 infants with hypoplasia of the left ventricle subjected to Glenn procedure, and in 34 out of 103 with closure of the ventricular septal defect. No association or statistically significant difference was found between short stature and cyanosis or univentricular physiology.

Conclusions. There is a high frequency of short stature among children with CHDs, with differences according to the type of CHD and cardiac surgery performed.

Key words: Growth disorders, short stature, malnutrition, congenital heart diseases, cardiopulmonary bypass pump.
\end{abstract}

http: / / dx.doi.org/10.5546/ aap.2019.eng.e211

Funding:

None.

Conflict of interest:

None.

Received: 8-30-2018

Accepted: 12-12-2018

To cite: Le Roy C, Larios G, Clavería C, Springmüller D. Short stature among children undergoing cardiac surgery for congenital heart defects. Arch Argent Pediatr 2019;117(3):e211-e217.

\section{INTRODUCTION}

It is well-known and studied that the risk of deficiency-related malnutrition among children with congenital heart diseases (CHDs) is higher since there are multiple factors that may affect, in a variable way, the different mechanisms of malnutrition, which, as a whole, account for the differences in the nutritional compromise based on the type of CHD. ${ }^{1-8}$

With appropriate medical management, nutritional support and cardiac surgery, weight and stature recovery is possible among children with CHDs. ${ }^{2,4,5,9}$

In children with a more severe chronic disease, such as a CHD, stunted growth or a short stature is a better indicator of nutritional compromise because it reflects the long-term consequence of deficiencyrelated malnutrition. ${ }^{10-12}$ The presence of short stature in patients with CHD varies widely, between $15 \%$ and $45.4 \%$, figures that are higher than in the healthy population. ${ }^{2,4-6,13-15}$ Statural catch-up after cardiac surgery is variable and the preoperative compromise of length/height is a prognostic factor. ${ }^{4,5,9,16}$

Our cardiac surgery center is one of the national reference institutions for children under 15 years of age having operable CHDs. Patients are admitted depending on their geographic distribution, not on the severity or type of CHD. The objective of this study was to describe the frequency of short stature according to the type of CHD and the specific surgical procedure performed.

\section{MATERIAL AND METHODS}

Non-concurrent cohort study. Patients with CHDs who underwent 
cardiac surgery (restorative or palliative) with cardiopulmonary bypass pump in the cardiac surgery center of the Clinical Hospital of the Pontificia Universidad Católica de Chile from January 2009 to December 2013 were studied.

Each of the cardiac surgical interventions performed during this period was analyzed. Since the objective of the research was to describe the frequency of short stature and some associated variables according to the type of $\mathrm{CHD}$ and the specific surgery performed, reinterventions for complications or with an interval of less than 30 days were not included.

Patients with other conditions that could have an impact on the nutritional status or that would render the interpretation of their nutritional assessment difficult, such as preterm infants (less than 37 weeks of gestation), small for gestational age, or who had a genetic syndrome or a second major chronic disease were excluded.

Demographic data were recorded as follows: gender, weight and length / height on the day prior to surgery, type of CHD, age at the time of surgery and type of surgery performed.

Congenital heart diseases were classified into univentricular and biventricular circulation according to the resulting circulation in the last surgery performed; and also, into cyanotic and non-cyanotic congenital heart diseases. Complexity in congenital heart surgery was evaluated using the Risk Adjustment for Congenital Heart Surgery (RACHS-1) classification, defining biventricular corrections (BVC) with a score $>3$ as complex. ${ }^{17}$

Z-score values were obtained using the World Health Organization (WHO) reference standards for each of the anthropometric indicators, weightfor-age Z-score by sex (WAZ), weight-for-length / height Z-score by sex (WHZ), body mass indexfor-age Z-score by sex (BMIZ) and length/heightfor-age Z-score by sex (HAZ), using Anthro v3.2.2 and Anthro plus v1.0.4. ${ }^{18,19}$

Short stature was defined if $\mathrm{HAZ}<-2$ standard deviations (SD), malnutrition if $\mathrm{WHZ}<-2 \mathrm{SD}$ in children under 5 years and, in children over 5 years, if BMIZ $<-2$ SD, excess weight if WHZ $>+1$ SD for children under 5 years and if BMIZ > +1 SD for children over 5 years. ${ }^{20}$

Statistical analysis was performed from an anonymized database with the STATA statistical software, version 12. Descriptive statistics were used, and categorical and discrete variables were expressed as absolute and relative frequency. For continuous variables, the Shapiro-Wilk normality test was used; variables that had a normal distribution were expressed as mean and SD, and those that did not have a normal distribution, as median and interquartile range (IQR: p 25; p 75). For analytical statistics, the chi-squared test, Spearman's rank correlation coefficient test and the Wilcoxon signed rank test were used comparing cyanotic with non-cyanotic congenital heart diseases. A $p$-value of $<0.05$ was set as the cutoff for significance.

In this study, ethical standards consistent with the Declaration of Helsinki (2013) were met and its approval was obtained from the Scientific Ethics Committee of Pontificia Universidad Católica de Chile (project number 14-032).

\section{RESULTS}

During this period, 876 heart surgeries were performed and 640 operations met inclusion criteria. These were performed on 557 subjects of whom $66(11.8 \%)$ required more than one cardiac surgery during this period. Congenital heart diseases that most frequently required more than one surgery were hypoplasia of the left ventricle (HLV) in 27 out of $66(40.9 \%)$, tetralogy of Fallot (TF) in 8 out of $66(12.1 \%)$ and tricuspid atresia in 8 out of $66(12.1 \%)$.

The median age was 8 months (IQR: 1.9; 34.6); 361 subjects were male, accounting for $56.4 \%$. A total of 147 newborn infants (younger than 30 days old) were operated, accounting for $23 \%$.

Table 1 outlines the main diagnoses corresponding to all the interventions included in this study; it shows those CHDs that were present in $>15$ subjects and, in the category "Others", 22 different diagnoses are described.

Univentricular CHDs were 196 (30.6\%) while biventricular ones were $444(69.4 \%)$. Among biventricular CHDs, 167 interventions $(37.6 \%)$ were BVCs.

TABLE 1. Main diagnosis of congenital heart disease

\begin{tabular}{lcc}
\hline Congenital heart disease & n & $\%$ \\
\hline Ventricular septal defect & 122 & 19.1 \\
Hypoplasia of the left ventricle & 94 & 15 \\
Tetralogy of Fallot & 82 & 12.8 \\
Transposition of the great arteries & 52 & 8.1 \\
Atrial septal defect & 47 & 7.3 \\
Tricuspid atresia & 30 & 4.7 \\
Double-outlet right ventricle & 29 & 4.5 \\
Total Anomalous Pulmonary Venous Drainage & 18 & 2.8 \\
Atrioventricular canal & 16 & 2.5 \\
Other & 150 & 23.2 \\
Total & 640 & 100 \\
\hline
\end{tabular}


Regarding the presence of cyanosis, $358(55.9 \%)$ were classified as cyanotic CHDs and $282(44.1 \%)$ as non-cyanotic.

The WHZ-BMIZ median was -0.2 (IQR: $-1.2 ; 0.8) ; 77$ patients $(12 \%)$ were malnourished and $132(20.7 \%)$ had excess weight.

The median HAZ was -0.9 (IQR: - $1.9,-0.1$ ); 135 subjects had short stature, accounting for $21.1 \%$. Evaluated by age, $11 \%$ of newborn infants and $24.1 \%$ of infants older than 30 days $(p=0.008)$ had short stature.

In children with univentricular $\mathrm{CHD}$, a median HAZ of -0.8 was found (IQR: $-1.7,0$ ); $33(17 \%)$ had short stature and, in biventricular CHD, a median HAZ of -1 (IQR: -1.9 ; -0.1 ) and $102(23 \%)$ had short stature. There was no statistically significant difference when analyzing univentricular and biventricular CHDs for median HAZ $(p=0.1)$ or the presence of short stature $(p=0.08)$.

Table 2 shows age variables, HAZ and short stature as per the classification of cyanosis. No difference in $\mathrm{HAZ}$ was found according to the presence of cyanosis $(p=0.2)$ nor association between cyanosis and short stature $(p=0.2)$. A statistically significant difference was found between the presence of cyanosis and the age of subjects $(p<0.0001)$; children with cyanosis were younger than those without cyanosis.

Table 3 shows age variables, HAZ and the presence of short stature corresponding to the diagnosis of CHDs with more than 15 infants subjected to the surgery that led to the hospital admission. A higher frequency of short stature was found in 4 out of 6 children $(66.7 \%)$ who underwent complete repair of the atrioventricular

TABLE 2. Age and length/height among children with congenital heart diseases according to the presence of cyanosis

\begin{tabular}{lccc}
\hline Outcome measure & Cyanosis & No cyanosis & $p$ \\
\hline $\mathrm{n}(\%)$ & $358(55.9)$ & $282(44.1)$ & - \\
Age (months old), median (IQR) & $6(0.4 ; 30.9)$ & $13.2(4.9 ; 45.4)$ & $<0.001$ \\
HAZ, median (IQR) & $-0.8(-1.7 ;-0.09)$ & $-1(-2 ;-0.08)$ & 0.2 \\
Short stature, $\mathrm{n}(\%)$ & $69(19.3)$ & $66(23.4)$ & 0.2 \\
\hline
\end{tabular}

${ }^{1} \mathrm{IQR}:$ interquartile range.

${ }^{2} \mathrm{HAZ}$ : Z-score for length/ height by age.

TABLE 3. Age and length/height among children with congenital heart diseases and type of intervention

\begin{tabular}{llcccc}
\hline Congenital heart disease & Intervention & $\mathbf{n}$ & $\begin{array}{c}\text { Age (months) } \\
\text { median (IQR) }\end{array}$ & $\begin{array}{c}\text { HAZ } \\
\text { median (IQR) }\end{array}$ & $\begin{array}{c}\text { Short stature } \\
\text { n (\%) }\end{array}$ \\
\hline Ventricular septal defect & Closure of ventricular & & & & \\
& septal defect & 103 & $6.8(4.4 ; 11)$ & $-1.5(-2.2 ;-0.9)$ & $34(33)$ \\
Hypoplasia of the left ventricle & Norwood & 40 & $0.3(0.2 ; 0.4)$ & $-1(-1.6 ; 0.3)$ & $4(10.3)$ \\
& Glenn & 25 & $8(6 ; 9)$ & $-1.1(-2.5 ;-0.8)$ & $8(33.3)$ \\
& Fontan & 28 & $36.8(33.2 ; 41)$ & $-0.4(-1.2 ; 0.4)$ & $3(10.7)$ \\
Tetralogy of Fallot & Patch repair of pulmonary & & & & \\
& stenosis & 26 & $3.3(2.3 ; 7)$ & $-0.9(-2.4 ;-0.4)$ & $9(34.6)$ \\
& Valve plasty/replacement & 17 & $116.7(79.6 ; 168.3)$ & $-0.8(-1.2 ; 0.2)$ & $2(11.8)$ \\
& Pulmonary artery repair & 13 & $16.4(5.8 ; 19.8)$ & $-2(-2.6 ;-1)$ & $6(46.2)$ \\
Transposition of the great arteries & Rastelli repair/switch & 42 & $0.2(0.2 ; 0.3)$ & $-0.7(-1.2 ; 0.3)$ & $4(9.5)$ \\
Atrial septal defect & Closure of atrial septal defect & 34 & $35.4(24.6 ; 59.5)$ & $-0.6(-1.6 ; 0.3)$ & $4(11.8)$ \\
& Repair of partial anomalous & & & & \\
& pulmonary venous drainage & 12 & $48.8(13.1 ; 85.6)$ & $-0.7(-2.2 ; 0.4)$ & $3(25)$ \\
Tricuspid atresia & Glenn & 11 & $7.9(6.8 ; 9.6)$ & $-1.5(-2 ;-0.7)$ & $3(27.3)$ \\
& Fontan & 9 & $34.4(33.9 ; 41.8)$ & $-0.2(-1 ; 0.02)$ & $1(11.1)$ \\
Double-outlet right ventricle & Biventricular repair & 14 & $5(2.5 ; 16.4)$ & $-1.1(-1.8 ;-0.6)$ & $2(14.3)$ \\
Total Anomalous Pulmonary & Repair of total anomalous & & & & \\
Venous Drainage & pulmonary venous drainage & 18 & $0.8(0.2 ; 3.6)$ & $-0.8(-1.8 ; 0.1)$ & $4(22.2)$ \\
Atrioventricular canal & Repair of incomplete canal & 7 & $26.1(21.4 ; 41.8)$ & $-0.9(-1.7 ;-0.5)$ & $1(14.3)$ \\
& Repair of complete canal & 6 & $4.2(3.8 ; 4.3)$ & $-2.9(-4 ;-1.7)$ & $4(66.7)$ \\
\hline
\end{tabular}

IQR: interquartile range; HAZ: Z-score for length/height by age. 
canal; in 6 out of $13(46.2 \%)$ infants with TOF subjected to repair of the pulmonary artery; in 9 out of $26(34.6 \%)$ children with TOF who underwent patch repair of pulmonary stenosis; in 8 out of 25 (32\%) infants with HLV subjected to Glenn surgery, and in 34 out of $103(33 \%)$ children with closure of the ventricular septal defect (VSD).

Figure 1 shows the absolute frequency of short stature according to the cardiological diagnosis and the specific cardiac surgery for which they were admitted.

When HAZ and other variables were analyzed, a correlation was found between the age and $\mathrm{HAZ}$ in the repair of total anomalous pulmonary venous drainage with an $r=-0.6(p=0.008)$ and in children with VSD who were admitted to undergo the VSD closure with an $r=0.3(p=0.003)$. There was a correlation between HAZ and WHZ-BMIZ in children with atrial septal defect (ASD) in whom the ASD closure was performed with an $r=0.4$ $(p=0.01)$ and in children with HLV who were admitted to be subjected to Norwood surgery with an $\mathrm{r}=-0.4(p=0.02)$.

\section{DISCUSSION}

A significant percentage of children and adolescents with CHDs who require surgery in our country are referred to our heart surgery center. The distribution of children who are referred is based on the geographic location and not on the diagnosis or surgical complexity, which may be reflected in the different diagnoses of CHDs, the type of surgery performed, the type of univentricular or biventricular physiology, and the presence of cyanosis. CHD surgery, surgical indications and medical-surgical followup of patients are regulated by guidelines of the Chilean explicit guarantees in healthcare program; however, the follow-up or nutritional management is not included. ${ }^{21}$

Of the total, $21.1 \%$ of children had short stature which is within the reported percentages. . $^{2,-6,13}$ Since the main objective was to describe the frequency of short stature related to the type of CHD and surgery, each of these interventions was included as a subject of study given that they corresponded to different physiological and hemodynamic times in their CHD. Consequently, it was not possible to determine the prevalence, as some of them were represented by the same patient more than once. The need of doing more than one surgery within the period studied was related to the fact that some congenital heart diseases required reoperations because of complications or residual defects.

FIGURE 1. Short stature among children with congenital heart diseases according to the cardiological diagnosis and cardiac surgery

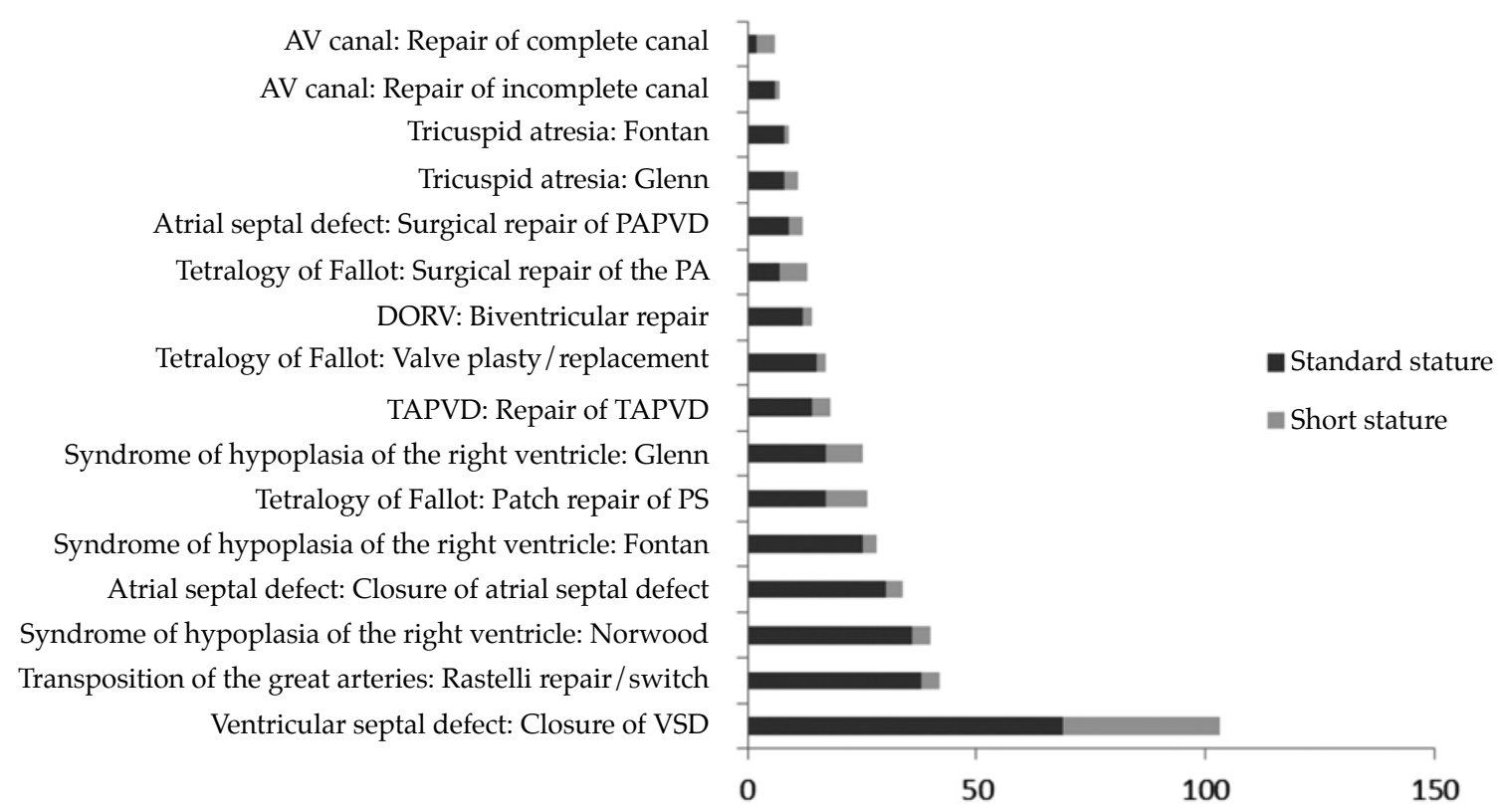

AV canal: atrioventricular canal; PAPVD: partial anomalous pulmonary vein drainage; PA: pulmonary artery; DORV: double outlet right ventricle; TAPVD: total anomalous pulmonary vein drainage; PS: pulmonary stenosis; ASD: atrial septal defect; VSD: ventricular septal defect. 
In some case-control studies, it is described that children with CHDs have the same birth weight as those without $\mathrm{CHD},{ }^{2,7}$; however, within their first months of life, their nutritional status becomes compromised. ${ }^{3,22}$ In this sample, it was found that, as of the first month of life, stature was compromised, which could be explained by a possible intrauterine growth restriction and / or by the impact of the CHD since birth up to the operation, in the context of a CHD with great hemodynamic impact and difficulties in achieving sufficient nutritional support. Since birth weight and length measurements were not available, it was not possible to evaluate this topic in depth. While the percentage of short stature in this group was higher than in the healthy population, it was significantly lower than that found in older children. This fact could be explained by a different distribution of CHD among these groups, conditioned by the usual moment of intervention. In infants older than 30 days, a longer time of systemic effect should be added compromising growth and stature. . $^{3,15,22}$

It should be pointed out that there was a high percentage of malnutrition, figures which are higher when compared with the healthy population of our country, although lower than in other studies of children with CHDs, but which makes the comparison of results difficult because the selection criteria for subjects are different among the different publications. . $^{2,5,13}$

Our global malnutrition score can be compared with a study in India, which found a higher percentage of malnutrition, $55.9 \%$. Economic, environmental, different health systems and even ethnic factors can account for this difference. ${ }^{5}$

It is remarkable the high percentage of excess weight found, which, although lower than in the pediatric population of the country, it is considered a health problem in children with CHD during the post-surgical follow-up. ${ }^{15,23,24}$ Excess weight is a factor of higher morbidity in chronic cardiovascular diseases and, acutely, it results in a higher rate of lower respiratory infections, a higher morbidity in patients in the Critical Unit or in the immediate postoperative period. Therefore, more attention should be paid to the nutritional support and a customized intervention should be carried out to avoid overfeeding. ${ }^{25-27}$

One finding that stands out is that no significant differences are found between short stature and cyanosis or between univentricular and biventricular physiology. This can be explained by the fact that children with VSD who were admitted to undergo a VSD closure, who have congenital heart disease without cyanosis and with biventricular physiology, had a high percentage of short stature comparable to that presented in those who were admitted with congenital heart disease with cyanosis and/or with univentricular physiology. 2,3

VSD and HLV have been selected for a more detailed description, due to the frequency of the children included and their high percentage of short stature.

Children admitted with ventricular septal defect diagnosis and ventricular septal closure surgery represented the largest number of interventions, with one of the highest percentages of short length/height, even greater than the percentage of short length/height for the entire sample. When compared to other publications, this percentage was higher than that of a recent study in Brazil, in which they presented $15 \%{ }^{4}$ This high percentage may account for the fact that no statistically significant difference was found when comparing the presence of low height according to the presence of cyanosis or univentricular physiology. ${ }^{1-3}$

Age at surgical closure of the ventricular septal defect has been studied as a prognostic factor in the recovery of nutritional deficiencies after cardiac surgery. It has been found, in longitudinal 2-year follow-up studies, that weight was recovered when surgery was performed at 11 months old versus 17 months and, if surgery was performed at around 5 months old, children experienced recovery of both WAZ and HAZ.4,

Our patients were operated with an intermediate age, but there is a lack of studies on recovery in our setting. In our country, indications for surgery to close a ventricular septal defect vary according to the time of onset of heart failure symptoms or hemodynamic compromise. It is worth noting that there is always the possibility that some defects will close spontaneously after the neonatal period and that there might be some mechanism for the spontaneous closure of the defect or its transformation into hemodynamically non-significant or without signs of heart failure when the defect becomes restrictive. Surgical repair of the ventricular septal defect in relation to these criteria is usually performed between 3 and 6 months old. In the national guidelines, one of the indications for VSD surgery is the nutritional status by WAZ, and no suggestion is made about using HAZ as well. It would be important to keep 
in mind how the stature is affected since the postsurgical recovery may be partial. $., 5,9,21$

In HLV, palliative surgical procedures are staged to achieve Fontan circulation and both the indication and the age or timing of each surgery will mainly depend on well-established hemodynamic aspects. Poor weight gain and short stature among infants with HLV has been published earlier and it has been shown that, in stage II (Glenn), they have a greater compromise of stature versus stage I (Norwood) and III (Fontan). ${ }^{16,28}$ In Table 3, these differences can also be seen. Findings are worth pointing out because, apparently, it is the natural course in this type of CHD, bearing in mind that this nutritional compromise runs parallel to complex hemodynamic changes, oxygen saturation, dyspnea, systemic perfusion that restrict or make possible nutritional status in each of the surgical stages. ${ }^{29,30}$

Major limitations of this work include its retrospective nature and that it was not possible to evaluate birth weight and length/ height, nutritional support, parental height, intercurrent morbidity, drugs, hospital stays, variables described as risk factors for developing nutritional deficiencies. ${ }^{1,5}$ Most patients were referred from other national heart centers only for surgery, so this data was not available in the clinical records.

This information will help evaluate medical and surgical indications as well as approaches that may improve the nutritional status of our patients in the short- and long-term.

To conclude, there was a high rate of short stature among children with CHDs, and there were differences according to the type of CHD and the cardiac surgery performed. No association with cyanosis or univentricular physiology was found, which could be explained by the high rate of short stature among children admitted to undergo a VSD closure.

\section{REFERENCES}

1. Blasquez A, Clouzeau H, Fayon M, Mouton JB, et al. Evaluation of nutritional status and support in children with congenital heart disease. Eur J Clin Nutr. 2016; 70(4):52831.

2. Okoromah CA, Ekure EN, Lesi FE, Okunowo WO, et al. Prevalence, profile and predictors of malnutrition in children with congenital heart defects: a case-control observational study. Arch Dis Child. 2011; 96(4):354-60.

3. Daymont C, Neal A, Prosnitz A, Cohen MS. Growth in children with congenital heart disease. Pediatrics. 2013; 131(1):e236-42.

4. Manso PH, Carmona F, Jácomo AD, Bettiol H, et al. Growth after ventricular septal defect repair: does defect size matter?
A 10 year experience. Acta Pædiatr. 2010; 99(9):1356-60.

5. Vaidyanathan B, Radhakrishnan R, Sarala DA, Sundaram $K R$, et al. What determines nutritional recovery in malnourished children after correction of congenital heart defects? Pediatrics. 2009; 124(2):e294-9.

6. Batte A, Lwabi P, Lubega S, Kiguli S, et al. Wasting, underweight and stunting among children with congenital heart disease presenting at Mulago hospital, Uganda. BMC Pediatr. 2017; 17(1):10.

7. Hansson L, Öhlund I, Lind T, Stecksén-BlicksC, etal.Dietary intake in infants with complex congenital heart disease: a case-control study on macro-micronutrient intake, meal frequency and growth. J Hum Nutr Diet. 2016; 29(1):67-74.

8. Farrell AG, Schamberger MS, Olson IL, Leitch CA. Large left to right shunts and congestive heart failure increase total energy expenditure in infants with ventricular septal defect. Am J Cardiol. 2001; 87(9):1128-31.

9. Correia Martins L, Lourenço R, Cordeiro S, Carvalho N, et al. Catch-up growth in term and preterm infants after surgical closure of ventricular septal defect in the first year of life. Eur J Pediatr. 2016; 175(4):573-9.

10. Waterlow JC. Classification and definition of protein-calorie malnutrition. Br Med J. 1972; 3(5826):566-9.

11. Mehta NM, Corkins MR, Lyman B, Malone A, et al. Defining pediatric malnutrition: A paradigm shift toward etiology-related definitions. JPEN Parenter Enteral Nutr. 2013; 37(4):460-81.

12. Becker PJ, Nieman Carney L, Corkins MR, Monczka J, et al. Consensus statement of the Academy of Nutrition and Dietetics/American Society for Parenteral and Enteral Nutrition: indicators recommended for the identification and documentation of pediatric malnutrition (undernutrition). J Acad Nutr Diet. 2014; 114(12):1988-2000.

13. Costello CL, Gellatly M, Daniel J, Justo RN, et al. Growth restriction in infants and young children with congenital heart disease. Congenit Heart Dis. 2015; 10(5):447-56.

14. LeRoy C, Larios G, SpringmüllerD, Clavería C. Diagnóstico nutricional en lactantes menores con cardiopatía congénita: comparación de dos clasificaciones antropométricas. Rev Chil Pediatr. 2017; 88(6):744-50.

15. Chile. Ministerio de Salud. Diagnóstico del estado nutricional de menores de 6 años, gestantes, nodrizas y adultos mayores, bajo control en el sistema público de salud. Santiago: Minsal; 2014. [Accessed on: December 2016]. Available at: http: / / www.minsal.cl/sites/default / files / DIAGNOSTICO_ESTADO_NUTRICIONAL_ DICIEMBRE_2013.pdf.

16. Anderson JB, Beekman RH 3rd, Eghtesady P, Kallwarf HJ, et al. Predictors of poor weight gain in infants with a single ventricle. J Pediatr. 2010; 157(3):407-13.

17. Jenkins KJ, Gauvreau K, Newburger JW, Spray TL, et al. Consensus-based method for risk adjustment for surgery for congenital heart disease. J Thorac Cardiovasc Surg. 2002; 123(1):110-8.

18. World Health Organization. Anthro (version 3.2.2, January 2011). [Accessed on: January 2016]. Available at: http:// www.who.int/childgrowth/software/es/.

19. World Health Organization. Anthro Plus version 1.0.4. [Accessed on: January 2016]. Available at: http://www. who.int/growthref/tools/en/.

20. Henkes SH (ed.). Norma técnica para la supervisión de niños y niñas de 0 a 9 años en la Atención Primaria de Salud. Programa Nacional de Salud de la Infancia. Santiago: Ministerio de Salud; 2014. [Accessedon: March 2015]. Available at: http://www.crececontigo. gob. cl/wp-content / uploads / 2015/11 / Norma-Tecnicapara-la-supervision-de-ninos-y-ninas-de-0-a-9-en-APS. compressed.pdf. 
21. Chile. Ministerio de Salud. Guía Clínica: Cardiopatías congénitas operables en menores de 15 años. Santiago: MINSAL; 2010. [Accessed on: December 2015]. Available at: https: / / www.minsal.cl/ portal/url/item/720bfefe91e 0d2ede04001011f010ff2.pdf.

22. Aguilar DC, Raff GW, Tancredi DJ, Griffin IJ. Childhood growth patterns following congenital heart disease. Cardiol Young. 2015; 25(6):1044-53.

23. Pinto NM, Marino BS, Wernovsky G, De Ferranti SD, et al. Obesity is a common comorbidity in children with congenital and acquired heart disease. Pediatrics. 2007; 120(5):e1157-64.

24. Tamayo C, Manlhiot C, Patterson K, Lalani S, et al. Longitudinal evaluation of the prevalence of overweight / obesity in children with congenital heart disease. Can J Cardiol. 2015; 31(2):117-23.

25. Buelow MW, Earing MG, Hill GD, Cohen SB, et al. The Impact of Obesity on Postoperative Outcomes in Adults with Congenital Heart Disease Undergoing Pulmonary Valve Replacement. Congenit Heart Dis. 2015; 10(5):E197-202.
26. Shamszad P, Rossano JW, Marino BS, Lowry AW, et al. Obesity and Diabetes Mellitus Adversely Affect Outcomes after Cardiac Surgery in Children's Hospitals. Congenit Heart Dis. 2016; 11(5):409-14.

27. Barbiero SM, D'AzevedoSica C, Schuh DS, Cesa CC, et al. Overweight and obesity in children with congenital heart disease: combination of risks for the future? BMC Pediatr. 2014; 14:271

28. Anderson JB, Kalkwarf HJ, Kehl JE, Eghtesady P, et al. Low weight for age $\mathrm{Z}$ score and infection risk after the Fontan procedure. Ann Thorac Surg. 2011; 91(5):1460-6.

29. Davis D, Davis S, Cotman K, Worley S, et al. Feeding difficulties and growth delay in children with hypoplastic left heart syndrome versus d-transposition of the great arteries. Pediatr Cardiol. 2008; 29(2):328-33.

30. Spillane NT, Kashyap S, Bateman D, Weindler M, et al. Comparison of feeding strategies for infants with hypoplastic left heart syndrome: a randomized controlled trial. World J Pediatr Congenit Heart Surg. 2016; 7(4):446-53. 